\title{
Evaluating the Effectiveness of Vinegar as a Sanitizer Journal Submission
}

\section{By Geeti Bhatti}

ENVH 8410

April 14, 2016 


\title{
Evaluating the Effectiveness of Vinegar as a Sanitizer
}

Geeti Bhatti ${ }^{1}$, Helen Heacock ${ }^{2}$

1 Lead Author, B.Tech Student, School of Health Sciences, British Columbia Institute of Technology, 3700 Willingdon Ave, Burnaby, BC V5G 3H2

2 Supervisor, School of Health Sciences, British Columbia Institute of Technology , 3700 Willingdon Ave, Burnaby, BC V5G 3H2

\begin{abstract}
Objectives: Pathogens are introduced into foods, surfaces, and hands by our surrounding environment which includes soil, air, and fecal contamination. It can be due to improper handling, cleaning, washing or sanitizing. Sanitizers are applied to surfaces in order to kill all the vegetative cells of microbes. Health Canada regulates the types, uses and concentration of the sanitizers. These sanitizers are chemically formulated to kill microbes and hence there is a rising concern about toxicity associated with their use. People are moving away from regulated sanitizers to natural alternatives. This research project examined the efficacy of vinegar, one of the natural alternatives, as a sanitizer.
\end{abstract}

Methods: 3M Quick Swabs were used to collect coliform samples from a plastic cutting board before and after inoculating it with coliform culture and subsequently cleaning it with vinegar. A one tail paired t-test was conducted to assess whether the coliform counts were reduced after cleaning with vinegar.

Results: For all 30 samples there was a reduction in the number of coliforms when comparing before and after cleaning with vinegar. Results show that there is a significant difference in the mean numbers of coliforms before and after cleaning with vinegar; $p<0.0001$.

Conclusion: These results indicate that undiluted vinegar when used for cleaning food contact surface significantly reduces the coliform counts but not to the safer levels for human exposure.

Keywords: sanitizer, vinegar, food contact surfaces, alternatives, efficacy

\section{Introduction}

A sanitizer is defined as an agent that reduces specific bacterial load by $99.999 \%$ in 30 seconds (1). Often log reduction values are used to determine the number of viable microbes eliminated from a given surface by either disinfecting or sanitizing (2). Health Canada has approved five sanitizers for the commercial settings: Chlorine, Acid Sanitizers, Hydrogen Peroxide, Quaternary ammonium compounds and lodophors (3). Due to concerns about chemicals and toxicity associated with commercial sanitizers, interest has emerged for more natural alternatives. Vinegar is one such product. The concentration of acetic acid in vinegar can vary from less than one, to more than 20 percent per ml. Health Canada regulates the concentration of acetic acid for human consumption at $4 \%$ to $6 \%$ but no regulations or standards exist for vinegar being used as a sanitizer. The results from the evidence review highlight some areas where more research is still required: concentration, contact-time, properties of antimicrobial are some to consider.

This report was authorized by Dr. Helen Heacock (Instructor at BCIT Environmental Health Program) and Mrs. Vanessa Karakilic (Instructor at BCIT Environmental Health Program). The reason for conducting this microbial survey was to highlight the efficacy of using vinegar as an alternative sanitizer as individuals are becoming concerned with the chemical toxicity associated with commercial sanitizers. Although issues with sanitization programs can lead to authoritative orders in the commercial settings by Public Health Inspectors, most importantly it impacts "allergen, microbiological, pest activity, and/or safety issues within the plant"(4). Thus, it is 
essential to use the correct sanitizer with appropriate concentrations and contact-times, in order to ensure effective sanitation that will help eliminate or reduce disease causing pathogens. Vinegar is one of the alternative sanitizers that is been used by many (3).

The focus of this study was be to evaluate the effectiveness of the Heinz white vinegar in reducing the number of coliforms on a food contact surface by performing microbial sampling before and after application of undiluted vinegar. The purpose of the proposed research study was to conduct microbial analysis that will aid in providing more details about the efficacy of vinegar, as an alternative to commercial sanitizers.

\section{Literature Review}

The literature review is based on the natural sanitizers that are emerging as an alternative to the commercial sanitizers and their effectiveness in providing a safe environment.

\section{Background}

There are four commonly used sanitizers for five contact surfaces: Chlorine, Acid Sanitizers, Hydrogen Peroxide, Quaternary ammonium compounds and lodophors (3). These are permitted as sanitizers by Health Canada. Alternatives to these sanitizers are: Tea tree oil, vinegar, baking soda, electrolyzed water, silver disinfectant and natural microfiber cloths (ENJO). These are used as a result of the public's toxicity concerns with commercial chemical sanitizers (3). This review will only focus on vinegar for further study.

Vinegar is the product of conversion of dilute ethyl alcohol to acetic acid by Acetobacter bacteria $(4,5)$. The main components of vinegar are water and acetic acid. Chemist $\mathrm{S}$. Tan discovered the sour liquid was acetic acid in the first half of eighteenth century (5). The colour and flavour are dependent on the raw material used such as: cider, beer, wine, sugars, starch, fermented fruit juices and solution of barley malt (6). The concentration of the acetic acid varies from 4 - $6 \%$ in regular household vinegar. However, higher concentrations may be found but restricted from human consumption (7). Vinegar has been used for over 10,000 years and manufactured flavoured vinegars have been sold for past 5000 years (5).

\section{Production Process}

The production of vinegar involves two steps of fermentation. First the sugars in raw material are converted to alcohol by yeast and, second the alcohol is oxidized to acetic acid by Acetobacter (8). Primarily grapes, apple and other fruits juices are used as starting material however, malt or rice may also be used (8). Predominately two methods are used:

a) Surface Method. This involves the culture of acetic acid bacteria growing on the surface of wood shavings and provides oxygen at the surface.

b) Submerged Culture. This involves the supply of oxygen to accelerate industrial production (8).Refer to figure 1 for the diagram.

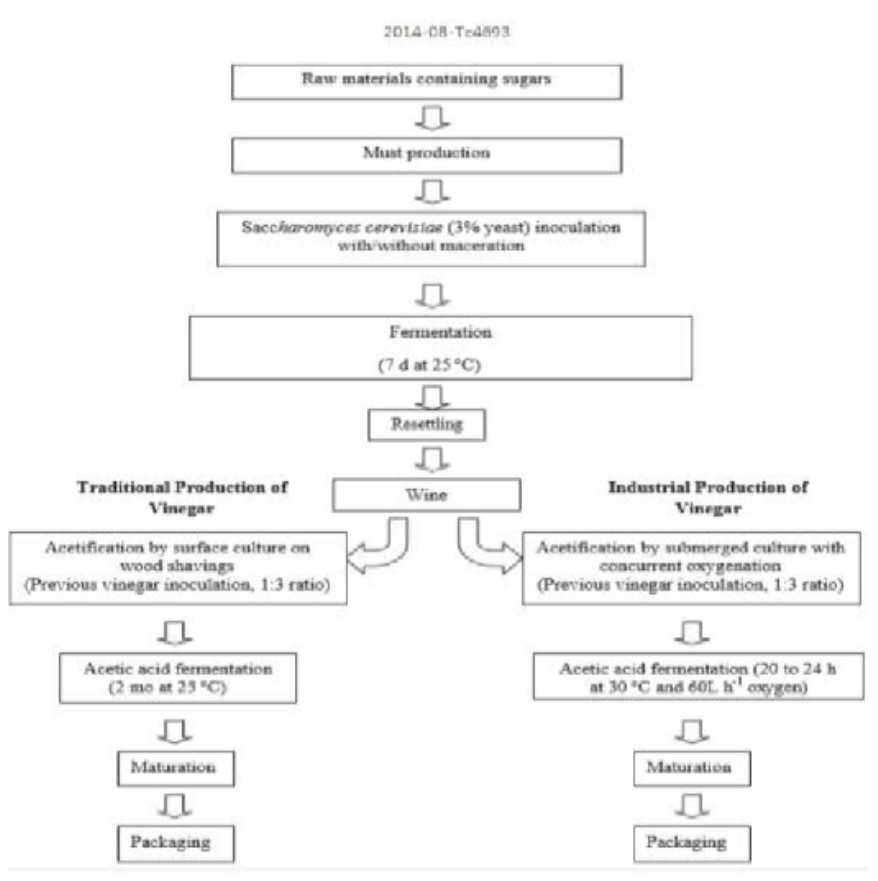

Figure 1: Typical vinegar production (8) 


\section{Public Health Significance}

From 10,000 years ago to the present, the raw material of vinegar has evolved and so has its uses. Its uses range from been a cooking ingredient, antimicrobial, preservative, to household cleaning agent $(6,9)$. Today people are seeking alternative sanitizers for domestic and commercial secondary food-contact surfaces.

Vinegar is used as an alternative and has a $\mathrm{pH}$ of 3. Most bacteria require neutral $\mathrm{pH}$ to survive but vinegar does not meet the definition of sanitizer prescribed by Health Canada. For a product to classify as a food contact surface sanitizer it should reduce "bacterial population on environmental surfaces and inanimate objects which may come into direct contact with food or beverages (e.g., eating and drinking utensils, cutting boards, countertops, food processing equipment) by significant numbers (e.g., a minimum 3 log10 reduction), but which does not destroy all bacteria"(10).

The use of vinegar can be traced back thousands of years and it has been labelled as safe by default. But rare cases involving adverse effects to vinegar ingestion have been reported (11). One of them was a case of a 39 year old woman who was diagnosed with "inflammation of the oropharynx and second-degree caustic injury of the esophagus and cardia" due to consumption of 1 tablespoon of rice vinegar in order to dislodge a crab shell piece from her throat (11). Chronic injury to esophageal resulting inflammation of esophagus poses a cancer risk (11).

\section{Categories of Vinegar}

Vinegar is classified as Class 1 Preservative by Health Canada. It can be used to preserve meat, fish, meat by-products etc, but the amounts are not specified (12). The Food Code sets the standards for concentration of sanitizers which have been evaluated for their effective results against the swab test but it does not set standards for alternatives being used (13). Because there are not set concentration standards for vinegar people tend to overuse it and this unintentional aspiration of vinegar can lead to "laryngospasm and subsequent vasovagal syncope" (11).

Vinegar is classified as an additive in foods like canned asparagus, creamed or processed or cold-pack cheese but again with no maximum levels that can be used (14). Since there are no limits on how much one can consume individuals try to set their own limits. In a report, a 28-year-old woman was consuming approximately $250 \mathrm{~mL}$ apple cider vinegar daily for 6 years and as a result, Hypokalemia was observed (11).

\section{Vinegar as Antimicrobial Agent}

Several studies have shown effectiveness of vinegar on microbes. In the study conducted by Krusong et al, the results showed that application of vinegar on the surface of fresh coriander with $8 \%$ acetic acid inhibited $K$. pneumoniae after 50 minutes $(15,20)$. Vinegar is a weak acid and hence it requires either higher concentration, which may pose a risk to human health, or increased contact time. Therefore, the combination of agents or factors can have synergistic effect of inhibiting microbes. In an experiment conducted by Lee et al to study the combined effects of heat and acid, it was concluded that there was higher reduction of E.coli 0157:H7 when treated with heat and vinegar than vinegar alone (4). However, production of chlorine gas is seen when vinegar is mixed with bleach (2).

Another study conducted by Bremer et al, showed that carrying out an acid wash step in addition to sanitation with chemicals during standard Clean-In-Place procedure is effective in removal of biofilms $(16,21)$. Vinegar is more effective in removing indigenous E.coli strain rather than one particular strain i.e. E.coli 0157:H7 (5). Undiluted vinegar seems to be effective against Giardia cysts but with contact time of 60 minutes at room temperature of 21 degree $C+/$ - 1 degree $C$ (17). However, 
complete inactivation of cysts was not achieved at any concentrations at 4 degree $C$ (17).

The necessity for disinfectants and sanitizers to be included in sanitation procedures has been endorsed by studies. These studies shows that cross-contamination risk from both food contact surfaces as well as environmental exposures are not effectively reduced by the use of detergents and washing alone $(18,19)$. Vinegar which has been used for years as a condiment, food additive \& preservative and therapeutic agent, is now trending towards being used as disinfectant and sanitizer. But the application of vinegar as a sanitizer in a commercial setting is limited due to its poor antimicrobial efficacy.

Many studies have demonstrated the effectiveness of vinegar on microbes but further research is required to support these results. There is a need for research to investigate contact time, concentration and stability of vinegar residuals. Besides these factors, the need of final rinse step in sanitation procedures should to be evaluated. The properties of antimicrobial agents need to be focused on more.

In this study the researcher evaluated the effectiveness of vinegar on food contact surfaces by evaluating the counts of colony forming units (CFUs) before and after cleaning the surfaces with Heinz cleaning undiluted vinegar.

\section{Purpose of the Study}

Health Canada regulates the use of commercial sanitizers in the commercial facilities like restaurants, daycare centers, and many more. Due to the concerns associated with the commercial sanitizers, people are choosing alternatives or natural sanitizers. Vinegar is one of many natural sanitizers that are used in different settings. Therefore, the purpose of this research project was to test the effectiveness of vinegar as a sanitizer. Microbial analysis was conducted to verify if the coliform counts decrease in numbers after cleaning with vinegar.

\section{Methods and Materials}

The null and alternate hypothesis for the study

$\mathrm{H}_{\mathrm{O}}$ : Mean number of coliforms after cleaning with Heinz vinegar $\geq$ Mean number of coliforms before cleaning with Heinz cleaning vinegar.

$\mathrm{H}_{\mathrm{A}}$ : Mean number of coliforms after cleaning with Heinz vinegar < Mean number of coliforms before cleaning with Heinz cleaning vinegar. 


\section{Description of Materials used}

For the purpose of this study, the following materials were used at the BCIT Food

Technology Laboratory.

\begin{tabular}{|c|c|}
\hline Materials & Description \\
\hline $\begin{array}{l}\text { Plastic } \\
\text { cutting } \\
\text { board }\end{array}$ & This was used as a food contact surface. \\
\hline $\begin{array}{l}\text { Tryptic } \\
\text { Soy Broth }\end{array}$ & $\begin{array}{l}\text { This was used as enrichment broth for the } \\
\text { coliforms growth }\end{array}$ \\
\hline $\begin{array}{l}\text { Peptone } \\
\text { water }\end{array}$ & $\begin{array}{l}\text { This was used as dilution blanks to have } \\
\text { countable plates for coliforms plated i.e. } \\
\text { plates with } 25 \text { cfus to } 250 \text { cfus. }\end{array}$ \\
\hline $\begin{array}{l}\text { Coliform } \\
\text { cultures }\end{array}$ & $\begin{array}{l}\text { The cultures were inoculated on the Plastic } \\
\text { cutting board before sampling and } \\
\text { cleaning. } \\
\text { This provided counts for the coliforms to } \\
\text { be compared. }\end{array}$ \\
\hline $\begin{array}{l}\text { Heinz } \\
\text { Vinegar }\end{array}$ & $\begin{array}{l}\text { This product was used as cleaning } \\
\text { agent for cleaning inoculated } \\
\text { surfaces. It is made from sun ripened } \\
\text { grain and diluted with water to } \\
\text { achieve } 5 \% \text { acidity ( } 22 \text { ). }\end{array}$ \\
\hline $\begin{array}{l}3 M^{\mathrm{TM}} \\
\text { Quick } \\
\text { swabs }\end{array}$ & $\begin{array}{l}\text { These were used to swab the plastic } \\
\text { cutting board. }\end{array}$ \\
\hline Vortex & $\begin{array}{l}\text { This releases bacteria from the cotton } \\
\text { swab. }\end{array}$ \\
\hline $\begin{array}{l}3 M^{T M} \\
\text { Petrifilm }^{T M}\end{array}$ & $\begin{array}{l}\text { This is a medium for growth of coliforms } \\
\text { after the sampling is performed. The } \\
\text { inoculum was spread evenly over the } \\
\text { surface before the Petrifilm plates were } \\
\text { incubated. }\end{array}$ \\
\hline Incubator & $\begin{array}{l}\text { This provided optimum temperature for } \\
\text { the growth of coliforms. } \\
\text { Temperature was maintained in closed } \\
\text { cabinet at } 35 \text { degree } C \text {. }\end{array}$ \\
\hline
\end{tabular}

\section{Preparation of peptone water}

$2 \mathrm{~g}$ of peptone medium was dissolved in 2 liters of purified water. It was mixed thoroughly and 9 $\mathrm{ml}$ was poured in the test tubes. Test tubes were autoclaved at $121^{\circ} \mathrm{C}$ for 15 minutes.
Preparation of Coliform cultures

For the purpose of this study E.coli will be referred to as coliform in general. E.coli is one of the pathogenic bacteria among the coliform group. If the product can eliminate pathogenic E.coli, one can conclude that it is effective against the less pathogenic forms of coliforms. Fresh coliform culture was prepared 24 hours prior to the inoculation of the surfaces. E.coli was plated by the lab technician. The researcher recovered the isolated colonies using the tryptic soy broth (TSB). Isolated colonies were inoculated in the tryptic soy broth using inoculum loop. The broth was incubated at 35 degree Celsius for 24 hours. $1 \mathrm{ml}$ of fresh coliform culture was diluted from $10^{\wedge} 9$ coliforms to $10^{\wedge} 3$ coliforms per $\mathrm{ml}$ using series of six $9 \mathrm{ml}$ peptone water test tubes.

\section{Preparation of sampling surfaces}

Plastic cutting boards were purchased from a dollar store. All thirty surfaces were divided into two portions of $5 \mathrm{~cm} \times 10 \mathrm{~cm}$ for sampling. Both portions were inoculated with $1 \mathrm{ml}$ of E.coli using the microliter pipette. Only one portion of the surface was inoculated with $1 \mathrm{ml}$ of Heinz white vinegar using a micropipette. They were evenly spread with gloved finger tips. The vinegar was allowed to have a contact time of 15 minutes. One portion was swabbed for coliform without vinegar and other was swabbed of coliforms with vinegar.

\section{Standard methods}

$3 M^{T M}$ Quick swabs: Pre-sterilized, premoistened $3 \mathrm{M}^{\mathrm{TM}}$ Quick swabs (Catalog No. 6433) were used to sample each area. Surfaces were inoculated with $1 \mathrm{ml}$ of coliform culture and spread evenly to the area of $5 \mathrm{~cm} \times 10 \mathrm{~cm}$ using gloved finger tips. Swabs were streaked directly onto the surfaces to be sampled and bent to snap the $1.1 \mathrm{ml}$ of contained fluid to moisten the swab. The swabs were vortexed to release the bacteria, and poured onto $3 \mathrm{M}^{\mathrm{TM}}$ Coliforms Petrifilm (23). 3M Quick swabs were used for dry sampling in collecting samples (26). This method involved 4 steps. Removal of swab from tube and swab targeted area. Swab was 
placed back into tube. Then red snap valve was bend to transfer all the broth into the tube. Next, tube was vortexed vigorously for 10 seconds to release bacteria from swab. Lastly, contents were poured onto a $3 \mathrm{M}$ Petrifilm Plate (23).

$3 M^{T M}$ Petrifilm ${ }^{T M}$ : The surfaces sampled with $3 \mathrm{M}^{\mathrm{TM}}$ Quick swabs (Catalog No. 6433)

described above were poured onto $3 \mathrm{M}^{\mathrm{TM}}$ Coliforms (Catalog No. 6410) Petrifilm. The inoculum was spread evenly over the surface before the Petrifilm plates were incubated at $35^{\circ} \mathrm{C}$ for 48 hours for coliform results (24).

Surfaces were inoculated with vinegar and the same procedure was followed to swab.

\section{Calibration of instruments}

For the purpose of this study the only equipment that needed to be calibrated was the incubator. Incubators are generally industry calibrated; however over time they require in house calibration. This can be done either by the person in-charge of equipment calibration or by calling for calibration services (25).

\section{Inclusion and Exclusion Criteria}

For the purpose of this study only the Heinz brand vinegar with $5 \%$ acetic acid was used. No other brand was used.

According to the Microgen Bioproducts Guide, environmental sampling is based on various zones that have different levels of risk associated with them (27). Typically, zones are divided into three areas: Zone 1, Zone 2, and Zone 3 but sometimes Zone 4 is considered a separate area (28). The hierarchy of zones is based on how vulnerable a product is to contamination if a pathogen is present in the zone in terms of pathways (28).
Zone 1 is associated with direct food-contact surfaces and is the most susceptible to contamination. These include cutting boards, knives, mixers, conveyors, utensils, racks, slabs, trays, work tables (28).

Zone 2 is associated with areas that are closest to zone 1 . This includes all non-food contact surfaces including equipment, framework, air and ventilation equipment, carts (28).

Zone 3 is associated with areas that are closest to zone 2 . These include hallways and doorways leading into and out of production areas, plastic blinds separating areas (28).

Zone 4 is associated with areas closest to zone 3 , and is the least susceptible to contamination. These areas include employee locker rooms, lunchrooms and cafeterias, washrooms, storage warehouses and loadingdock areas (28).

When deciding on sampling areas, these were only restricted to plastic cutting boards in the Zone 1 . Zones 2, 3 and 4 were excluded from this study.

\section{Statistical analysis and Results}

\section{Type of data}

The researcher collected discrete numeric data i.e. colony forming units counts.

The discrete numeric data is in the form of whole number (31).

\section{Descriptive Data}

The discrete numeric data was collected and logged into the Microsoft Excel to generate the descriptive statistics charts. Figure 1 outlines the results for the data obtained. Overall counts for coliforms decreased after the application of the vinegar to the cutting boards. For cutting board number 7 the coliforms count was 8 cfus. 
It is an outlier in the experiment which could have occurred during sampling or application of vinegar.

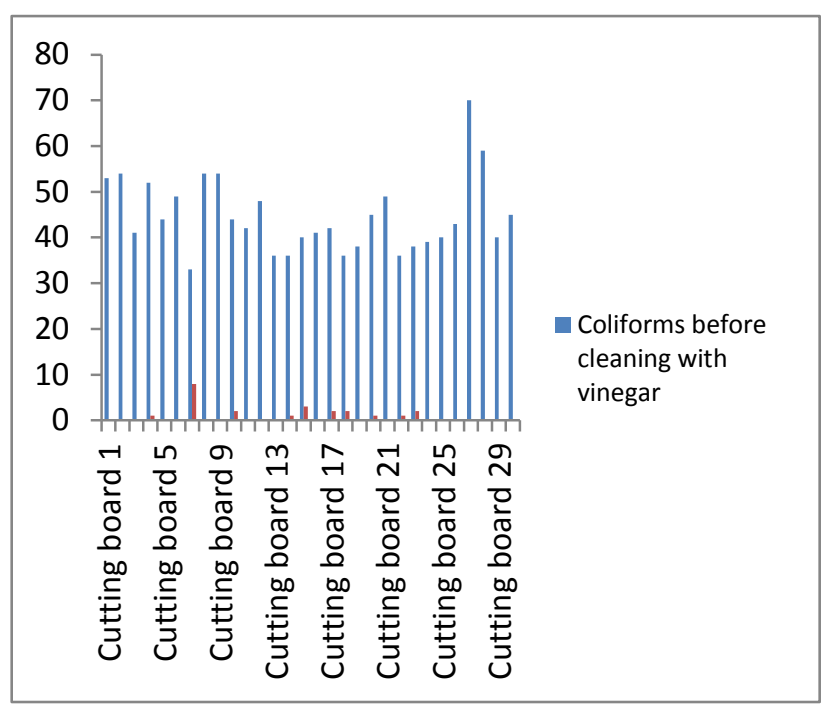

Figure 1: Coliform counts for plastic cutting board before and after cleaning with vinegar.

\begin{tabular}{|l|l|l|l|}
\hline $\begin{array}{l}\text { Coliforms before } \\
\text { cleaning with } \\
\text { vinegar }\end{array}$ & & $\begin{array}{l}\text { Coliforms after } \\
\text { leaning with } \\
\text { vinegar }\end{array}$ & \\
\hline Mean & 44.7 & Mean & 0.8 \\
\hline Standard Error & 1.4 & Standard Error & 0.2 \\
\hline Median & 42.5 & Median & 0 \\
\hline Mode & 36 & Mode & 0 \\
\hline $\begin{array}{l}\text { Standard } \\
\text { Deviation }\end{array}$ & 8.1 & $\begin{array}{l}\text { Standard } \\
\text { Deviation }\end{array}$ & 1.6 \\
\hline $\begin{array}{l}\text { Sample } \\
\text { Variance }\end{array}$ & 67.1 & $\begin{array}{l}\text { Sample } \\
\text { Variance }\end{array}$ & 2.5 \\
\hline Range & 37 & Range & 8 \\
\hline Minimum & 33 & Minimum & 0 \\
\hline Maximum & 70 & Maximum & 8 \\
\hline Sum & 1341 & Sum & 23 \\
\hline Count & 30 & Count & 30 \\
\hline $\begin{array}{l}\text { Confidence } \\
\text { Level (95.0\%) }\end{array}$ & 3.0 & $\begin{array}{l}\text { Confidence } \\
\text { Level (95.0\%) }\end{array}$ & 0.6 \\
\hline
\end{tabular}

Figure 2: Descriptive Statistics for Coliform counts before and after cleaning with vinegar (29).

Figure 2 outlines the results for the data, the mean coliform count before and after cleaning with vinegar differed greatly 44.7 CFUs and 0.8
CFUs respectively (29). This shows the efficacy of vinegar as a cleaning agent.

\section{Data run without the outlier}

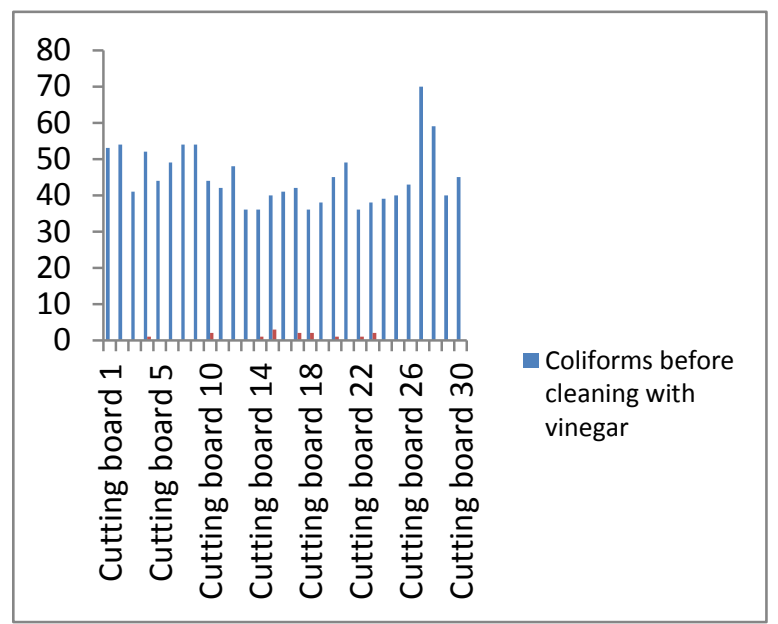

Figure 3: Coliform counts for Plastic cutting before and after cleaning with vinegar without an outlier.

\begin{tabular}{|c|c|c|c|}
\hline $\begin{array}{l}\text { Coliforms before } \\
\text { cleaning with } \\
\text { vinegar }\end{array}$ & & $\begin{array}{c}\text { Coliforms after } \\
\text { cleaning with } \\
\text { vinegar }\end{array}$ & \\
\hline Mean & 45.1 & Mean & 0.5 \\
\hline Standard Error & 1.4 & Standard Error & 0.1 \\
\hline Median & 43 & Median & 0 \\
\hline Mode & 36 & Mode & 0 \\
\hline $\begin{array}{l}\text { Standard } \\
\text { Deviation }\end{array}$ & 8.0 & $\begin{array}{l}\text { Standard } \\
\text { Deviation }\end{array}$ & 0.8 \\
\hline Sample Variance & 64.5 & Sample Variance & 0.7 \\
\hline Range & 34 & Range & 3 \\
\hline Minimum & 36 & Minimum & 0 \\
\hline Maximum & 70 & Maximum & 3 \\
\hline Sum & 1308 & Sum & 15 \\
\hline Count & 29 & Count & 29 \\
\hline $\begin{array}{l}\text { Confidence Level } \\
(95.0 \%)\end{array}$ & 3.0 & $\begin{array}{l}\text { Confidence Level } \\
(95.0 \%)\end{array}$ & 0.3 \\
\hline
\end{tabular}

Figure 4: Descriptive Statistics for Coliform counts before and after cleaning with vinegar without an outlier (29) 


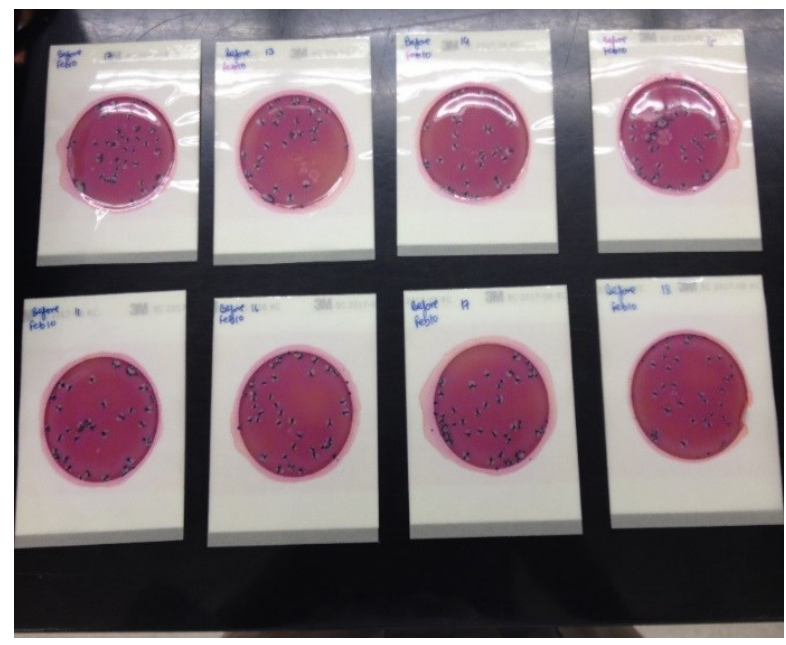

Figure 5: Petrifilms with Coliforms growth.

The mean coliform count before and after cleaning with vinegar differed grealty $45.1 \mathrm{CFUs}$ and 0.5 CFUs respectivelty.

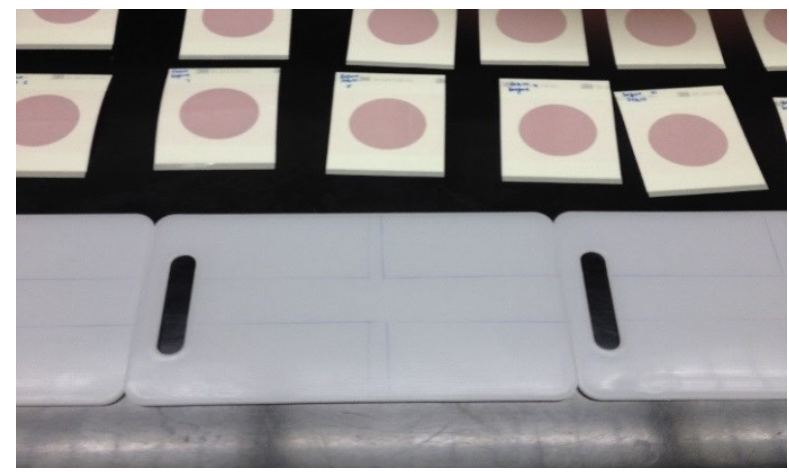

Figure 6: Plastic cutting boards divided into portion of $5 \mathrm{~cm} \times 10 \mathrm{~cm}$

\section{Inferential statistics}

The researcher conducted a one tail paired ttest because it is comparing different means between two dependent groups (numeric data) (32). Groups are divided as coliform counts before cleaning with vinegar and coliform counts after cleaning with vinegar.

\section{Statistical Package Used}

Two statistical packages were used to generate results. The data was entered by the researcher in the Microsoft Excel and descriptive statistical results were obtained for analysis (29). SAS-University-Edition was used to perform one tail paired t-test (32).

\section{Data run}

Data sheet

Refer to Appendix A Table 1.

Results from SAS

Refer to Appendix B

\section{Interpretation}

The statistical test chosen was one tail paired ttest. The data was non parametric, therefore, the Wilcoxon Signed Rank test was used.

Coliform counts were entered in Microsoft Excel. Results indicate that there is a significant difference in the mean numbers of coliforms before and after cleaning with vinegar with $p$ value $<0.0001$ (33).

At the $p$-value $<0.0001$, we can conclude that there is a statistically significant difference in the mean numbers of coliforms before and after cleaning with the vinegar therefore, reject the null hypothesis. We can conclude that vinegar is a successful nonfood contact sanitizer agent (kills most of the pathogenic microbes) but cannot be used as a food contact sanitizer because it did not kill all the pathogenic microbes.

\section{Alpha and Beta Error}

It was unlikely that the difference occurred by chance because $p$-value $<0.0001$. Therefore, type 1 error is unlikely to have occurred.

There was no beta error because the null hypothesis was rejected.

\section{Discussion}

In the study vinegar was tested for its efficiency as a sanitizer. Vinegar is commonly used as an alternative to chemical sanitizers due to concerns with toxicity related with the chemical residue from these products. A total of thirty plastic cutting boards were inoculated with coliform culture and cleaned with Heinz undiluted vinegar. Samples were swabbed before and after cleaning with vinegar. The results of the study showed a statistically 
significant reduction in E.coli counts before and after cleaning with vinegar with $p<0.0001$.

Sanitizers regulated by Health Canada include Chlorine, Acid Sanitizers, Hydrogen Peroxide, Quaternary ammonium compounds and lodophors, and these are permitted to be used on food contact surfaces (3). There are many other alternatives to these sanitizers such as vinegar, tea tree oil, electrolyzed water, silver disinfectant and natural microfiber cloths (ENJO) (2). Vinegar is an alternative sanitizers that has been used widely (3).

Vinegar has been shown to be effective in reducing the number of coliforms. One study assessed the combined effects of heat and acid, and concluded that there was higher reduction of E.coli 0157:H7 when treated with heat and vinegar than vinegar alone (23). In this experiment, a reduction in the E.coli was seen at room temperature.

In a study conducted by Santos et al vinegar used to treat lettuce inoculated with E.coil was more effective in removing the indigenous E.coli strain rather than one particular strain i.e. E.coli 0157:H7 (25). The researcher found similar results to this study in that the E.coli counts were reduced to zero in almost all samples.

In this study $1 \mathrm{ml}$ of $5 \%$ vinegar was left on the surface for 15 minutes with $1 \mathrm{ml}$ inoculum the mean coliform count before and after cleaning with vinegar differed grealty 45 CFUs and 0.5 CFUs respectivelty. However in the study conducted by Krusong et al, the results showed that application of vinegar on the surface of fresh coriander with $8 \%$ acetic acid inhibited $\mathrm{K}$. pneumoniae after 50 minutes $(7,20)$. Both E.coli and K.pneumoniae are gram negative rod shaped bacteria. The difference in kill time could be related to the initial bacterial counts on the surface. Greater initial counts require higher concentration and contact time to kill all microbes.
The researcher used $1 \mathrm{ml}$ of $5 \%$ vinegar to eliminate up to 70 E.coli in 15 minutes. However people tend to overuse certain natural sanitizers without knowing the proper concentration required. As such, adverse health effect can occur. For example, a 39 year old woman was diagnosed with "inflammation of the oropharynx and second-degree caustic injury of the esophagus and cardia" due to consumption of 1 tablespoon of rice vinegar in order to dislodge a crab shell piece from her throat (20). Chronic injury to the esophageal resulting in inflammation of the esophagus poses a cancer risk (20). If higher concentration of vinegar is used on the surfaces and people are exposed to it through food coming in contact or ingestion there is a possibility that they may develop serious health conditions.

Hence it is important to use the proper concentration of vinegar to avoid possible adverse health effects. This study clearly demonstrated that at $5 \%$ concentration vinegar is effective at reducing E.coli from plastic cutting boards. We conclude that vinegar is a successful non-food contact sanitizing agent (kills most of the pathogenic microbes) but cannot be used as a food contact sanitizer because it doesn't kill all the pathogenic microbes.

\section{Limitation}

Time was a major limitation for this project. Initially it was proposed that the researcher would use Heinz cleaning vinegar but it remained out of stock in Canada and Untied States Walmart during the entire project period. Therefore, for the purpose of this experiment regular Heinz white vinegar was used. Hence generalizability to cleaning vinegar is not possible. However, it may be more likely that the general public uses regular vinegar for cleaning especially if the Heinz cleaning vinegar is difficult to obtain.

Due to time constraints, different concentrations and different contact times 
were unable to be examined. A study conducted by Bremer et al showed that undiluted vinegar was effective against Giardia cysts but with contact time of 60 minutes at room temperature of 21 degree $C+/-1$ degree $C$ (17). However, complete inactivation of cysts was not achieved at any concentrations at 4 degrees $C$ (17). This experiment was not performed at different temperature but was restricted to room temperature.

\section{Conclusion}

Based on the results it can be and concluded that there is a statistically significant difference in the mean numbers of coliforms before cleaning with the vinegar and after cleaning with the vinegar $(p<0.0001)$. Power was $100 \%$. Therefore there were no alpha or beta errors and it can be concluded that based on the results of this study, vinegar was truly able to reduce E.coli counts on plastic cutting boards from a mean of 45 cfus to a mean of 0.5 cfus. Hence, vinegar can be used as a non-food contact surface sanitizer i.e. killing most of the bacteria but not all pathogenic microbes.

\section{Recommendations}

Vinegar can be used as a non-food contact surface sanitizer.

The study findings can allow health inspectors to make educated decisions when they observe vinegar being used in either home or commercial settings. In order to eliminate $1 \mathrm{ml}$ of coliforms from the surface only $1 \mathrm{ml}$ of undiluted vinegar is required with at least 15 minutes of contact time. However, in the study some samples did not result in zero count of E.coli. This result needs further sampling because even one E.coli is considered as a public health concern. EHOs can use this information to educate the operators or people who wish to apply vinegar in different settings. It is very important to know the concentrations of the vinegar being applied to the surfaces. Higher concentrations i.e. more than $5 \%$ acetic acid may be found but are restricted from human consumption (30). EHOs should educate the users about dangers of mixing of vinegar with other cleaning products. The most common product used in every setting is bleach. People might mix bleach with vinegar but this poses a serious health concern, due to production of chlorine gas (2).

\section{Future research suggestions}

To make this experiment more broadly applicable different materials for the surface sampling can be used such as steel which is commonly found in food service establishments. Vinegar can be used to clean many surfaces with varying temperatures. Temperature plays a role in proliferating or inhibiting microbes. It would be useful to test efficacy of vinegar at two different temperatures commonly used by people and compare the effectiveness between each group: refrigeration (4 degree $\mathrm{C}$ ) and room (20 degree C).

There is a lot of research required in approving vinegar as sanitizer. Indigenous E.coli culture was used for the purpose of this experiment. Although it is one of the pathogenic microbes, testing vinegar against other commonly found pathogens like Salmonella in food can be very helpful. There is a need to investigate contact time, concentration and stability of vinegar residuals. Besides these factors, the need of final rinse step in sanitation procedures should to be evaluated. The properties of antimicrobial agents need to be focused on more. By performing this experiment with different surface materials, acetic acid concentration, contact-times, microbes of concern and temperatures it can be a great addition to the research already available. Results can be further used to develop guidelines for the application of vinegar on food contact and nonfood contact surfaces. 


\section{Reference}

1. Reeve L. The Importance of Sanitation Quality Assurance \& Food Safety [Internet]. Quality Assurance \& Food Safety. 2015 [cited 14 October 2015]. Available from: http://www.qualityassurancemag.com/article /aib0614-plant-sanitation-program

2. Fong D, Gaulin C, Lê, M, Shum M.

Disinfectants and sanitizers for use on food contact surfaces [Internet]. 2015 [cited 14 October 2015]. Available from: http://www.bccdc.ca/NR/rdonlyres/E9C003D 1-E781-498B-9210E3E6A623D96C/0/EHSeminarDec122011_Alte rnative_antimicrobial_agents.pdf

3. The Vinegar Institute. Cleaning With Vinegar [Internet]. 2015 [cited 14 October 2015]. Available from:

http://www.versatilevinegar.org/pdf/Cleanin g\%20with\%20Vinegar.pdf

4. Lee S, Kang D. Combined effects of heat, acetic acid, and salt for inactivating Escherichia coli 0157:H7 in laboratory media. Food Control [serial on the Internet]. (2009, Nov), [cited October 14, 2015]; 20(11): 10061012. Available from: Academic Search Complete.

5. Santos $Y$, Almeida R, Guimaraes A, Almeida $P$. Hygienic- sanitary quality of vegetables and evaluation of treatments for the elimination of indigenous E.coli and E.coli 0157:H7 from the surface of leaves of lettuce (Lactuca sativa L.). Food Science and Technology Abstract. 2010;30(4):1083-1089.

6. Tan S. Vinegar Fermentation [Internet]. 2005 [cited 14 October 2015]. Available from: http://ucfoodsafety.ucdavis.edu/files/192137 .pdf
7. Vinegar. Columbia Electronic Encyclopedia, 6Th Edition [serial on the Internet]. (2015, June), [cited October 14, 2015]; 1. Available from: Academic Search Complete.

8. Laws-lois.justice.gc.ca. Food and Drug Regulations [Internet]. 2015 [cited 14 October 2015]. Available from: http://lawslois.justice.gc.ca/eng/regulations/c.r.c.,_c._87 0/page-164.html\#h-115

9. Budak N, Aykin E, Seydim A, Greene A, Guzel-Seydim Z. Functional Properties of Vinegar. Journal of Food Science.

2014;79(5):R757-R764.

10. Nthenge A, Chen F, Godwin S. Efficacy of home washing methods in controlling surface microbial contamination on fresh produce. Journal of Food Protection. 2005;69(2):330334.

11. Hc-sc.gc.ca. Guidance Document: Disinfectant Drugs [Internet]. 2015 [cited 14 October 2015]. Available from: http://www.hc-sc.gc.ca/dhp$\mathrm{mps} /$ prodpharma/applic-demande/guideId/disinfect-desinfect/disin_desineng.php\#a141

12. Carol S. Johnston C. Vinegar: Medicinal Uses and Antiglycemic Effect. Medscape General Medicine [Internet]. 2006 [cited 15 October 2015];8(2):61. Available from: http://www.ncbi.nlm.nih.gov/pmc/articles/P MC1785201/

13. Hc-sc.gc.ca. Permitted Preservatives - Lists of Permitted Food Additives - Health Canada [Internet]. 2015 [cited 14 October 2015]. Available from: http://www.hc-sc.gc.ca/fnan/securit/addit/list/11-preserv-conserveng.php

14. Food Retail and Food Services Code [Internet]. 2004 [cited 14 October 2015]. 
Available from:

http://foodsafe.ca/resources/Food_Services_ Code2004.pdf

15. Hc-sc.gc.ca. Lists of Permitted Food Additives - Health Canada [Internet]. 2015 [cited 15 October 2015]. Available from: http://www.hc-sc.gc.ca/fnan/securit/addit/list/index-eng.php

16. Krusong W, Teerarak M, Laosinwattana C. Liquid and vapour-phase vinegar reduces Klebsiella pneumoniae on fresh coriander. Food Control. 2015;50:502-508.

17. Bremer P, Fillery S, McQuillan A. Laboratory scale Clean-In-Place studies on the effectiveness of different caustic and acid wash steps on the removal of dairy biofilms. International Journal of Food Microbiology. 2005;106(200):254-262.

18.Costa A, Thomaz Soccol V, Paulino R, Alcantara de Castro E. Effect of vinegar on the viability of Giardia duodenalis cysts. International Journal Of Food Microbiology [serial on the Internet]. (2009, Jan 1), [cited October 14, 2015]; 128(3): 510-512. Available from: FSTA - Food Science and Technology Abstracts.

19. Barker J, Naeeni M, Bloomfield SF. The effects of cleaning and disinfection in reducing Salmonella contamination in a laboratory model kitchen. J Appl Microbiol. 2003;95(6):1351-60.

20.Heinz Vinegar. Heinz ${ }^{\circledR}$ Cleaning Vinegar [Internet]. 2015 [cited 9 November 2015]. Available from: http://www.heinzvinegar.com/productscleaning-vinegar.aspx Cdc.gov. CDC -

21. Healthyfacilitiesinstitute.com. Infection Prevention: Basics of Log Reduction - Healthy Facilities Institute ${ }^{\circledR}$ [Internet]. 2015 [cited 9
November 2015]. Available from:

http://www.healthyfacilitiesinstitute.com/a_ 50-Basics_of_Log_Reduction

22 Disinfection \& Sterilization Guideline:Glossary - HICPAC [Internet]. 2015 [cited 9 November 2015]. Available from: http://www.cdc.gov/hicpac/Disinfection_Ster ilization/19_00glossary.html

23. Solutions.3m.com. 3M ${ }^{\mathrm{TM}}$ Food Safety Website - Product Catalog: $3 \mathrm{M}^{\mathrm{TM}}$ Petrifilm ${ }^{\mathrm{TM}}$ E.coli/Coliform Count Plates [Internet]. 2015 [cited 9 November 2015]. Available from: http://solutions.3m.com/wps/portal/3M/en_ US/Microbiology/FoodSafety/productinformation/productcatalog/?PC_Z7_RJH9U523003DC023S7P92O 3087000000_nid=COWJ62882Vbe29BDXSBJ7 $\mathrm{Fgl}$

24. Eoma.aoac.org. Official Methods of Analysis [Internet]. 2015 [cited 11 November 2015]. Available from:

http://www.eoma.aoac.org/methods/info.as $p$ ?ID $=46949$

25. Food Technology Food 2020 Food Microbiology. 3rd ed. Burnaby: British Columbia Institute of Technology; 2007.

26. Lahou E, Uyttendaele M. Evaluation of Three Swabbing Devices for Detection of Listeria monocytogenes on Different Types of Food Contact Surfaces. International Journal of Environmental Research and Public Health. 2014;11(1):804-814.

27. Microgen Bioproducts Ltd. A Guide to Environmental Microbiological Testing for the Food Industry [Internet]. [cited 8 November 2015]. Available from: http://www.microgenbioproducts.com/Path_ Chek\%20Pathogen/Path\%20Chek\%20Guide\% 20to\%20Environmental\%20Monitoring_09.05 .08\%20_9_.pdf 
28. Michigan Department of Agriculture \& Rural Development. Understanding the Environmental Monitoring Concept [Internet]. 2012 [cited 9 November 2015]. Available from:

http://www.michigan.gov/documents/mdard /Understanding_the_Environmental_Monitor ing_Zone_Concept_375002_7.pdf.

29. Microsoft Excel 2010. Vancouver:

Microsoft Office; 2010.

30. Multi Media. $3 \mathrm{M}^{\mathrm{TM}}$ Petrifilm ${ }^{\mathrm{TM}}$ Plate Certificates, Recognitions and Validations [Internet]. [cited 10 November 2015].

Available from: http://multimedia.3m.com/mws/media/2411 $880 / 3 m$-petrifilm-plate-certificates-

recognitions-validations.pdf

31. Heacock H. Research Methods Module 4. Lecture presented at; 2015; BCIT.

32. Heacock H. Research Methods Module:5 Inferential Statistics. Lecture presented at; 2015; BCIT.

33. SAS-University-Edition. United States: VMware Technology; 2015. 


\section{Appendix A}

Table 1: Raw Data

\begin{tabular}{|c|c|c|}
\hline Areas of Sampling & $\begin{array}{c}\text { Coliforms before } \\
\text { cleaning with vinegar }\end{array}$ & $\begin{array}{l}\text { Coliforms after } \\
\text { cleaning with } \\
\text { vinegar }\end{array}$ \\
\hline Cutting board 1 & 53 & 0 \\
\hline Cutting board 2 & 54 & o \\
\hline Cutting board 3 & 41 & 0 \\
\hline Cutting board 4 & 52 & 1 \\
\hline Cutting board 5 & 44 & 0 \\
\hline Cutting board 6 & 49 & 0 \\
\hline Cutting board 8 & 54 & 0 \\
\hline Cutting board 9 & 54 & io \\
\hline Cutting board 10 & 44 & 2 \\
\hline Cutting boand 11 & 42 & 0 \\
\hline Cutting board 12 & 48 & 0 \\
\hline Cutting board 13 & 36 & 0 \\
\hline Cutting board 14 & 36 & 1 \\
\hline Cutting boand 15 & 40 & 3 \\
\hline Cutting boand 16 & 41 & 0 \\
\hline
\end{tabular}




\begin{tabular}{|c|c|c|}
\hline Cutting board 17 & 42 & 2 \\
\hline Cutting board 18 & 36 & 2 \\
\hline Cutting board 19 & 38 & 0 \\
\hline Cutting board 20 & 45 & 1 \\
\hline Cutting board 21 & 49 & 0 \\
\hline Cutting board 22 & 36 & 1 \\
\hline Cutting board 23 & 38 & 2 \\
\hline Cutting board 24 & 39 & 0 \\
\hline Cutting board 25 & 40 & 0 \\
\hline Cutting board 26 & 43 & 0 \\
\hline Cutting board 27 & 70 & 0 \\
\hline Cutting board 28 & 59 & 0 \\
\hline Cutting board 29 & 40 & 0 \\
\hline Cutting board 30 & 45 & 0 \\
\hline
\end{tabular}

Note cutting board number 7 is excluded

from the experiment 
Appendix B: SAS Results

\begin{tabular}{|l|l|l|l|l|}
\hline \multicolumn{5}{|c|}{ Tests for Normality } \\
\hline Test & \multicolumn{2}{|c|}{ Statistic } & \multicolumn{2}{c|}{ p Value } \\
\hline Shapiro-Wilk & W & 0.910203 & $\operatorname{Pr}<$ W & 0.0173 \\
\hline Kolmogorov-Smirnov & D & 0.148597 & $\operatorname{Pr}>$ D & 0.0979 \\
\hline Cramer-von Mises & W-Sq & 0.118795 & $\begin{array}{l}\operatorname{Pr}>\text { W- } \\
\text { Sq }\end{array}$ & 0.0617 \\
\hline Anderson-Darling & A-Sq & 0.732952 & $\operatorname{Pr}>$ A-Sq & 0.0496 \\
\hline
\end{tabular}

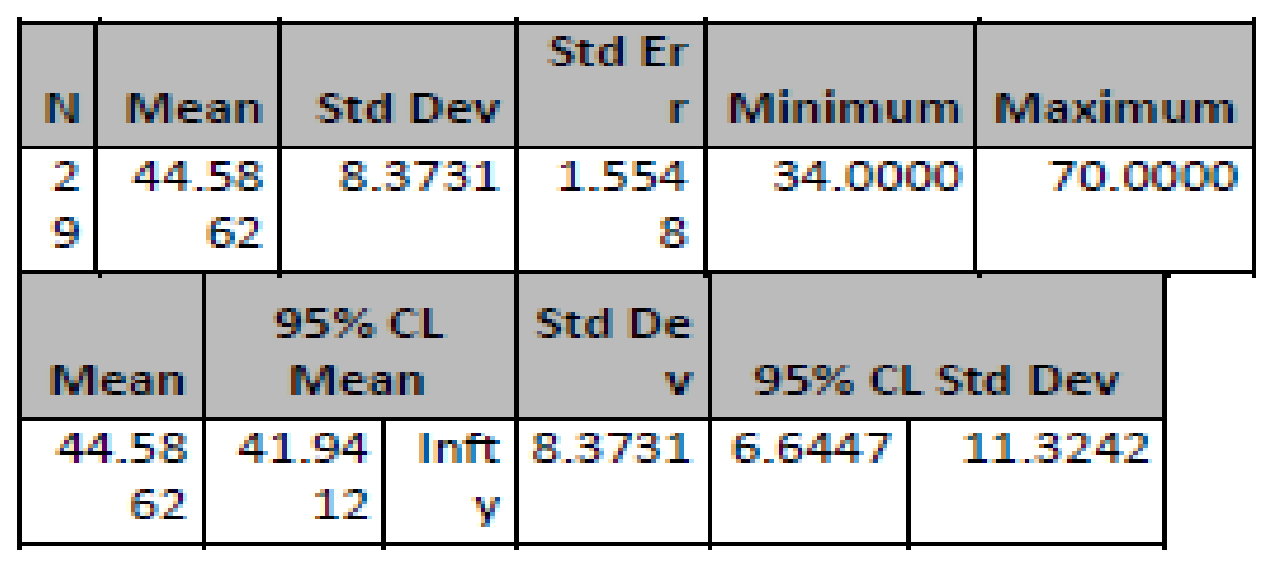

\begin{tabular}{|r|r|r|}
\hline DF & t Valu & Pr $>t$ \\
\hline 28 & 28.68 & $<.000$ \\
& & 1 \\
\hline
\end{tabular}

\begin{tabular}{|l|l|r|l|l|}
\hline \multicolumn{3}{|c|}{ Tests for Location: Mu0=0 } \\
\hline Test & \multicolumn{2}{|c|}{ Statistic } & \multicolumn{2}{c|}{ p Value } \\
\hline Student's t & t & 28.67574 & Pr $>~|t|$ & $<.0001$ \\
\hline Sign & M & 14.5 & $\begin{array}{l}\text { Pr }>= \\
\mid \text { M } \mid\end{array}$ & $<.0001$ \\
\hline Signed Rank & S & 217.5 & $\begin{array}{l}\text { Pr }>= \\
\text { |S | }\end{array}$ & $<.0001$ \\
\hline
\end{tabular}



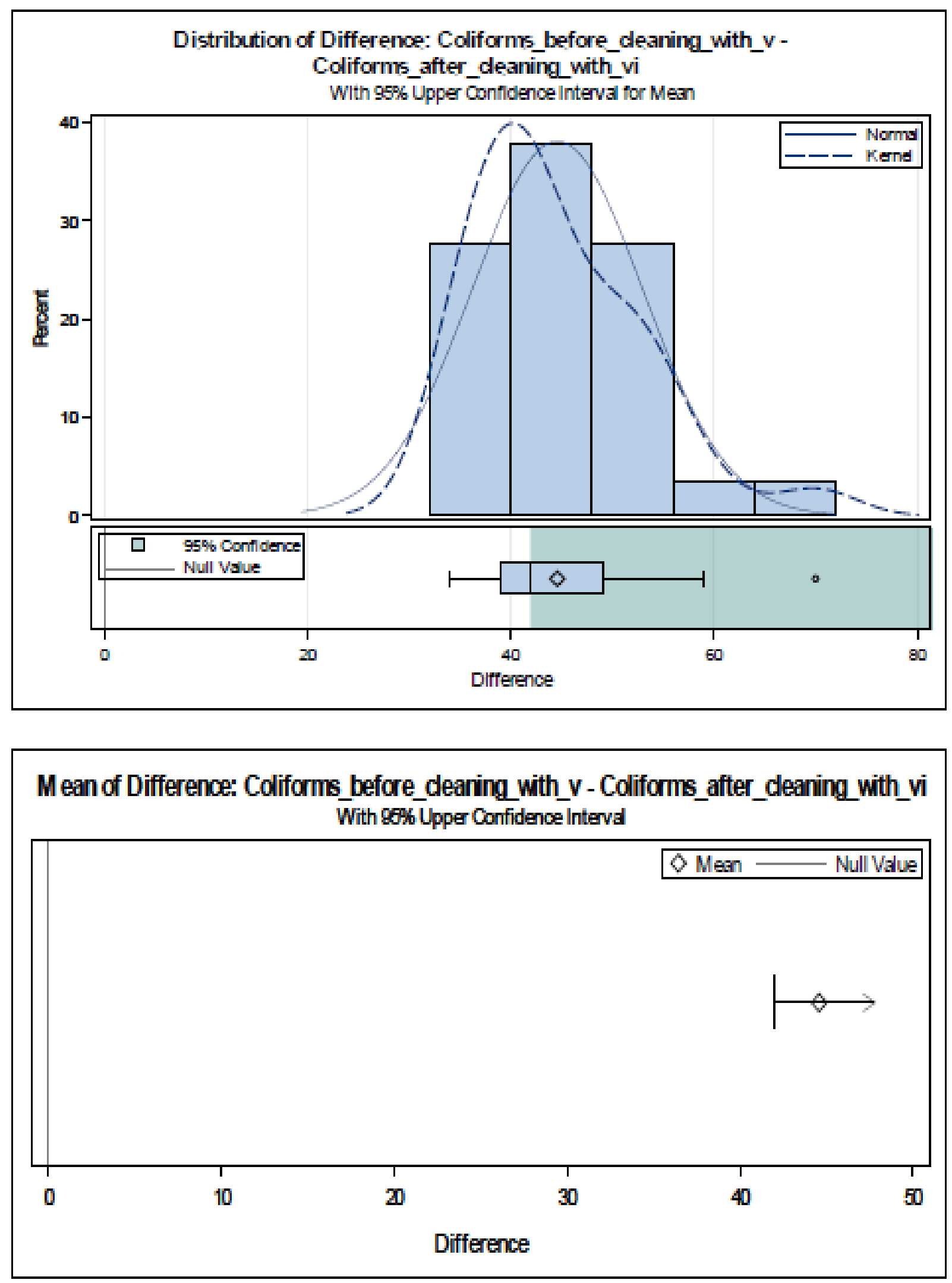


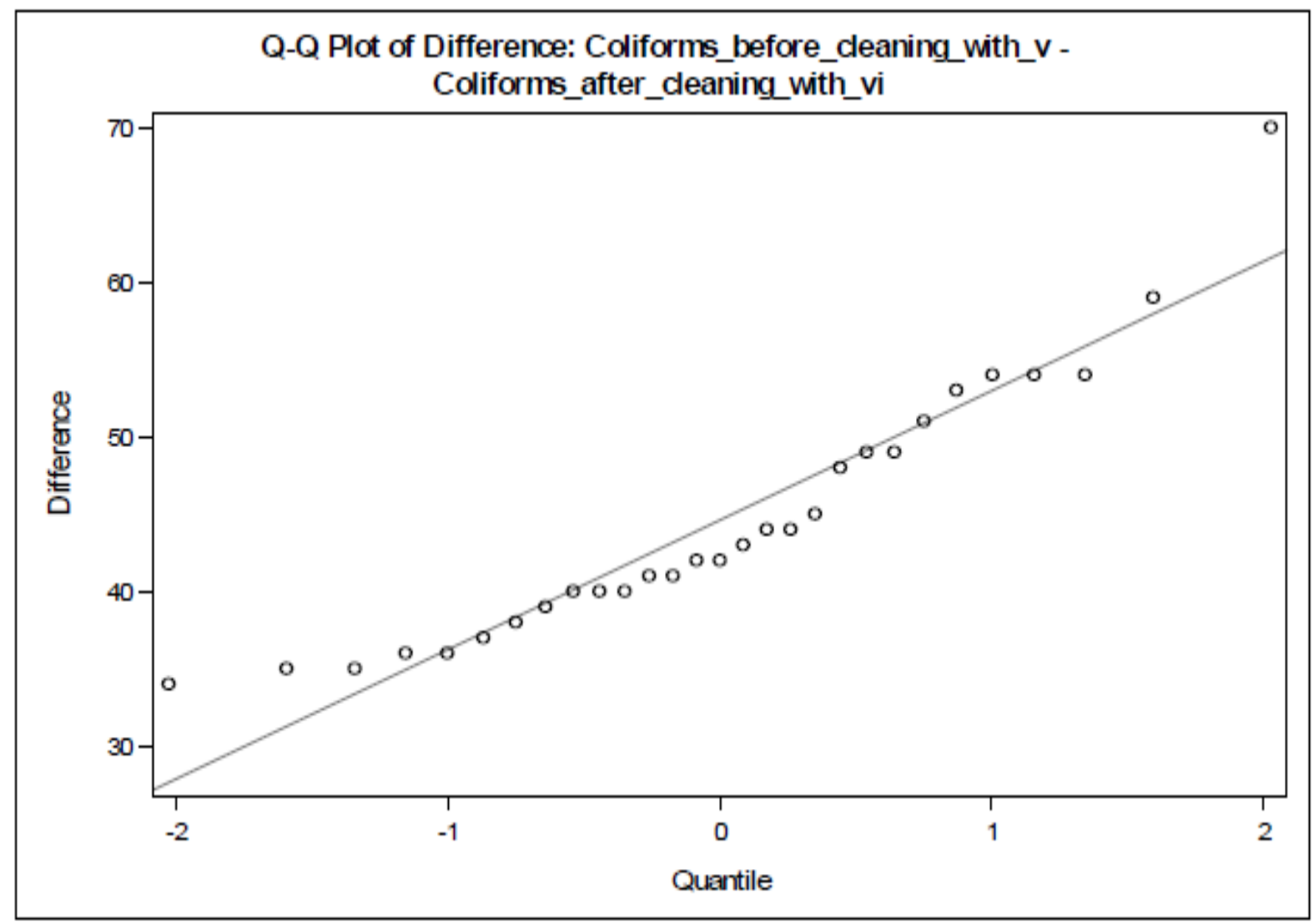

